\title{
Analisis Penjadwalan Pembangunan Intake Bendungan Karalloe Paket II Kabupaten Gowa dengan Metode PERT
}

\author{
Gita Wulandari Silo*1, Josefine Ernestine Latupeirissa*2 , Ari Kusuma*3 \\ *1 Mahasiswa Program Studi Teknik Sipil, Universitas Kristen Indonesia Paulus, Makassar, Indonesia \\ gitasilo03@gmail.com \\ *2-3 Dosen Program Studi Teknik Sipil, Universitas Kristen Indonesia Paulus, Makassar, Indonesia \\ Josefine ernestine@yahoo.com dan arykusuma6@gmail.com
}

\begin{abstract}
ABSTRAK
Perencanaan waktu yang baik sangat dibutuhkan dalam penjadwalan proyek agar dapat dipastikan bahwa perencanaan proyek yang ditetapkan dapat tercapai dengan kesalahan paling kecil namun dengan hasil maksimal dengan mendayagunakan apa yang ada. Sebab itu, periode menjadi salah satu hal penting selain biaya untuk menyelesaikan suatu proyek. Jaringan kerja atau Network Planning adalah suatu cara manajemen dalam perencanaan serta pengendalian suatu proyek, yang menyajiakn jangka waktu pekerjaan suatu aktivitas dan waktu proyek serta menunjukkan keterkaitan masing-masing pekerjaan. Penelitian ini menggunakan model PERT (Evaluasi Program dan Teknik Pengulasan). Model PERT adalah cara yang mempunyai tujuan untuk memprediksi berapa lama sebuah proyek serta menghitung perkiraan kemungkinan waktu yang digunakan. Dalam menghitung besar te (time expectted) dari model PERT, membutuhkan informasi a (kejadian optimistic), b (kejadian pesimistik), $\mathrm{m}$ (kejadian yang sangat memugkinkan ada). Penelitian dilapangan berguna untuk menghasilkan time schedule. Dengan durasi perhitungan cara PERT, didapatkan durasi pembangunan Bendungan Karalloe Paket II Kabupaten Gowa menggunakan cara PERT. Dari Time Schedule kontraktor didapatkan waktu membangun bendungan sekitar 120 minggu. Pada perhitungan metode PERT didapatkan durasi paling cepat dapat diselesaikan selama 88 Minggu, paling lambat diselesaikan selama 151 Minggu dan paling mungkin diselesaikan selama 128 Minggu.
\end{abstract}

Kata kunci : Metode PERT,Network Planning,Time Schedule

\begin{abstract}
Good time planning is needed in project scheduling so that it can be ensured that the specified project planning can be achieved with the smallest error but with maximum results by utilizing existing resources. Therefore, the period becomes one of the important things besides the cost to complete a project. Network planning is a management method for planning and controlling a project, which presents the work duration of an activity and project time and shows the relationship between each work. This study used PERT model (Evaluation Program and Review Technique). Model PERT is a method that has the aim of predicting how long a project will be and calculating the estimated possible time used. In calculating the amount of t.e. (time expected) of the PERT model, it requires information a (optimistic event), b (pessimistic event), $m$ (highly probable event). Field research is useful for generating time schedules. With the duration of the PERT method calculation, the duration of the construction of the Karalloe Dam Package II in Gowa Regency was obtained using the PERT method. From the contractor's Time Schedule, it was found that the time to build the dam was around 120 weeks. In the calculation of the PERT method, it is found that the fastest duration can be completed for 88 weeks, the latest is completed for 151 weeks and the most likely is completed for 128 weeks.
\end{abstract}

Keywords: PERT Method,Network Planning,Time Schedule

\section{PENDAHULUAN}

Salah satu hal yang sering menjadi ukuran kesuksesan pada suatu proyek konstruksi adalah penjadwalan proyek, selain perencanaan biaya dan kualitas. Jadwal harus diperhatikan dalam manajemen proyek untuk menentukan waktu ataupun urutan pekerjan proyek, agar penjadwalan menjadi lebih tepat. Pada dasarnya, penjadwalan proyek selalu menggunakan perencanaan waktu yang pasti. Tetapi, terdapat beberapa faktor ketidakpastian sehingga waktu setiap pekerjaan tidak dapat dipastikan dengan tepat. Salah satu hal pemicu ketidakpastian waktu yaitu cuaca, efektifitas tenaga kerja, dan sebagainya.

Metode yang sering digunakan dalam penjadwalan adalah Bar Chart kombinasi dengan kurva $S$ atau CPM. Jangka waktu yang dipakai pada metode tersebut dinyatakan itu sudah diketahui sudah nyatata. Model penjadwalan lainnya adalah metode Program Evaluation Review Technique (PERT). Metode PERT biasanya lebih menekankan pada usaha untuk mendapatkan jangka waktu yang 
paling tepat. Membagi - bagi proyek dalam beberapa kegiatan biasanya dilakukan dalam perencanaan dengan menggunakan PERT, seperti elemen-elemen kecil dari pekerjan dan untuk setiap pekerjan tertentu dibuatkan durasi yang akan diperlukan agar semua pekerjan mendapatkan proses yang akurat dalam penyelesaianya.

Alasan mengapa penelitian ini memilih menggunakan metode PERT,karena ada beberapa kelebihan yang dimiliki oleh metode PERT sendiri yang tidak ada pada metode penjadwalan lainnya yaitu penggunaannya yang tidak terlalu rumit,dapat mengetahui kapan proyek tersebut akan diselesaikan,juga dapat membaca kegiatan kritis yang tertunda jika proyek lambat dikrjakan.

Penelitian tentang penjadwalan proyek dengan metode PERT akan digunakan pada objek penelitian yaitu Bendungan Karalloe Paket II Gowa sebagai lokasi penelitian, khususnya penjdawalan dalam pekerjaan pembangunan Intake. Proyek konstruksi ini adalah salah satu proyek konstruksi skala besar di kawasan Sulawesi Selatan yang dapat dijadikan sebagai objek kajian penelitian yang menarik dalam mekanisme dan tata kelola pada proyek ini.

Suatu proyek pada konstruksi adalah serangkaian pekerjan saling bersinambung dalam mendapatkan suatu target (bangunan/konstruksi) pada jangka waktu, upah, dan kualitas tertentu. Merencanakan pekerjan-pekerjan proyek adalah masalah yang sungguh penting sebab perencanan pekerjan adalah dasar pada proyek agar bisa berjalan dan selesai pada waktu yang tepat.[1] Penentuan jadwal proyek, ada dua hal yang harus diperhatikan,yaitu : a.Earliest Start (ES) : waktu awal terhadulu yaitu waktu paling awal ketika suatu pekerjaan dimulai, b.Early finish (EF) : selesai dahulu yaitu waktu paling awal saat suatu pekerjaan diselesaikan, c. Latest start (LS) : memulai terakhir mengambarkan waktu toleransi akhir dimana pekerjaan harus dimulai, d. Latest finish (LF) : selesai terkhir ialah waktu toleransi terkhir pada setiap pekerjaan.[2]

Dalam perencanan dengan model PERT, suatu proyek terbagi menjadi bayak bagian dan pekerjaan kecil dari pekerjan dan masing-masing pekerjaan ditntukan durasi yang diperlukan sehinga setiap pekerjan direncnakan untuk waktu penyelesian dengan cermat.[3] Pekerjan Konstruksi akan baik apabila dikerjakan seperti yang sudah dirancangkan, atau pekerjan dapat terlaksana dengan tepat [4]

Perencanaan dasar berupa biaya atau jadwal pokok harus fleksibel, yang berarti dapat beradaptasi jika dirasa perlu, seperti terdapat perubahan keadan dan kondisi pada saat pekerjaan yang tidak bisa diprediksi ketika menyusun anggaran dasar[5]
Bagian terpenting dari suatu pekerjan adalah perencanan proyeknya, tujuanya untuk menetukan kapan satu pekerjan dapat dimulai pelaksananya, deretan pengerjaanya, bagian biayannya, dan waktu yang diperlukannya.[6] Bendungan merupakan suatu bangunan yang memiliki fungsi yaitu sebagai peninggi muka air dan penyimpanan pada saat musim hujan pada saat air sungai mengalir dalam kapasitas besar yang melebihi kebutuhan untuk air minum industri, keperluan irigasi, dan lain-lain. Model PERT digunakan jika pekerjan yang dilakuan berulang kali dan terusmenerus.[7]

Dalam penyusunan jadwal diperlukan pemikiran secara mendalam dengan berbagai permasalahan, mengukur rute tertentu dan menyusuhn berbagai jenis yang dihasilkan pada satu pekerjan dan mencantumkan berbagai kegiatan tersebut dengan waktu yang tepat( A. Luthan,hal 1,2006).[8] Pada dasarnya, prosedur pelaksanaan penjadwalan dengan proses perencanaan memiliki sifat yang tidak pasti. Kerena itu dibutukan suatu langkah untuk menghasilkan titik maksimal keterkaitan dengan waktu dan angaran pekerjan, sehinga boleh mendapatkan kenaikan biaya yang sedikit untuk memperpendek durasi pelaksanan pekerjan.[9]

PERT awalnya dikembangkan pada tahun 1958 dan 1959 untuk memenuhi kebutuhan zaman rekayasa massif sebagai pengembangan dari metode Bar chart ketika tidak dapat diterapkan. PERT adalah suatu metode yang digunakan untuk analisa jaringan. Analisa jaringan mempunyai tujuan membantu setiap penjadwalan yang saling berkaitan. Kegiatan ini bertujuan untuk setiap pekerjaan bisa dilaksanakan dengan terarah, agar mendapatkan keakuratan kerja. Metode PERT ditunjukkan melalui bagan yang menggambarkan suatu proyek. Bagan ini terdiri dari itik (nodes) yang menunjukkan kejadian.

Langkah dalam membuat metode PERT yaitu : a.Aktivitas, b.Kejadian, c.waktu pekerjan d.taksiran waktu selesainya pekerjan, jalur kritis. Perubahan teknologi menambah perkembangan disetiap lokasi, baik itu perkotan atau pedesan [10]

Tujuan dari penelitian ini adalah Menganalisis umur proyek pembangunan Intake pada Bendungan Karalloe Paket II berdasarkan penjadwalan dengan Metode PERT dan memahami parameter periode antar perencanan metode PERT beserta jadwal yang direncankan.

\section{METODE PENELITIAN}

\section{Tempat dan Waktu Penelitian}

Observasi ini dilakukan pada kegiatan pembangnan Bendungan Karalloe Paket II Gowa. Pekerjaan proyek pembangunan Bendungan Karalloe terletak di desa Garing-Datara, Kecamatan Tompobulu dan 
Biring Bulu, Kabupaten Gowa Provinsi Sulawesi Selatan. Jarak perjalanan kurang lebih 110 kilometer dari kota Makassar dengan waktu tempu 3 jam mengunakan roda-empat perjalanan Daerah Irigasi. Tempat penelitian ditunjukan pada gambaar 1.

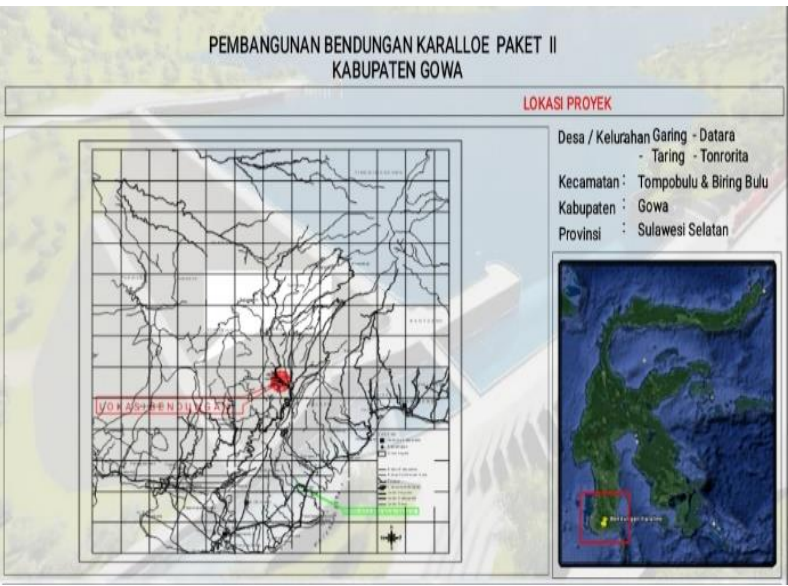

Gambar 1. Lokasi Penelitian

\section{Jenis Penelitian}

Riset yang dibuat bersifat deskriptif yakni riset kepustakan, wawncara dan juga survei lapangan. Pengumpulan informasi dicoba dengan dua kategori informasi, ialah informasi primer serta informasi sekhunder sebagai penunjang penelitian tentang pembangunan Intake Bendungan Karalloe.

\section{Pengambilan Data}

Pengambilan data bertujuan agar mendapatkan data yang dibutuhkan agar menghasilakn tujuan dari penelitian. Adapun Jenis peneltiian yang digunakan yaitu :

\section{a. Data Primer}

Data primer merupsakan Informasi yang didapatkan dari lokasi sebagai akar data yang ada padah saat melaksanakan Kerja Praktek pada Bendungan Karalloe Paket II Gowa khususnya pada pembangunan Intake.

b.Data Sekunder

Data sekunder yaitu data pendamping yang didaptkan dari lapangan oleh anggota perusahan di proyek. Data sekunder pada penelitian ini yaitu time schedule dan RAB yang diperoleh dari kontraktor pelaksana.

\section{ANALISIS DAN PEMBAHASAN}

Tahapan penyusunan sebagai berikut:

a. Menyusun jaringan kerja.

b. Menentukan tiga asumsi durasi aktivitas yaitu: waktu optimistik, waktu realistik, dan waktu pesimistik.
Tabel 1. Tiga Asumsi Durasi

\begin{tabular}{|c|c|c|c|c|c|c|}
\hline \multirow{2}{*}{$\begin{array}{l}\mathbf{N} \\
\mathbf{0} \\
.\end{array}$} & \multirow[t]{2}{*}{ URAIAN PEKERJAAN } & \multirow{2}{*}{$\begin{array}{l}\text { K } \\
\text { O } \\
\mathrm{D} \\
\mathrm{E}\end{array}$} & \multirow[b]{2}{*}{$\begin{array}{l}\mathbf{L} \\
\mathbf{A} \\
\mathbf{N} \\
\mathbf{J} \\
\mathbf{U} \\
\mathbf{T} \\
\mathbf{A} \\
\mathbf{N}\end{array}$} & \multicolumn{3}{|c|}{ DURASI (MINGGU) } \\
\hline & & & & $\begin{array}{l}\text { Opti } \\
\text { misti } \\
\text { k (a) }\end{array}$ & $\begin{array}{l}\text { Real } \\
\text { istik } \\
(\mathrm{m})\end{array}$ & $\begin{array}{l}\text { Pesi } \\
\text { misti } \\
\mathrm{k}(\mathrm{b})\end{array}$ \\
\hline 1 & \multicolumn{6}{|c|}{ PEKERJAAN PERSIAPAN (ITEM UMUM) } \\
\hline & $\begin{array}{l}\text { Mobilisasi peralatan } \\
\text { konstruksi,penyediaan } \\
\text { fasilitas kantor dan air } \\
\text { bersih }\end{array}$ & A & $\stackrel{B}{\mathrm{C}}$ & 5 & 6 & 7 \\
\hline 2 & \multicolumn{6}{|c|}{ PEKERJAAN DEWATERING } \\
\hline & $\begin{array}{l}\text { Dewatering selama } \\
\text { konstruksi di galian } \\
\text { terbuka dan galian di } \\
\text { dalam terowongan }\end{array}$ & B & $\mathrm{D}$ & 10 & 12 & 14 \\
\hline 3 & \multicolumn{6}{|c|}{ PEKERJAAN TANAH } \\
\hline & $\begin{array}{l}\text { Galian, semua jenis, di } \\
\text { dalam terowongan }\end{array}$ & $\mathrm{D}$ & $\mathrm{F}$ & 10 & 12 & 14 \\
\hline & $\begin{array}{l}\text { Timbunan kembali, } \\
\text { material random, } \\
\text { dibelakang bangunan }\end{array}$ & $\mathrm{F}$ & $\dot{H}$ & 1 & 2 & 3 \\
\hline
\end{tabular}

\section{PROTECTION AND SUPPORT WORKS}

\begin{tabular}{|c|c|c|c|c|c|}
\hline $\begin{array}{l}\text { Besi Penyangga (steel } \\
\text { support) termasuk } \\
\text { aksesoris, di dalam } \\
\text { terowongan }\end{array}$ & $\mathrm{G}$ & I & 3 & 4 & 6 \\
\hline
\end{tabular}

\begin{tabular}{|c|c|c|c|c|c|}
\hline $\begin{array}{c}\text { Proteksi dengan } \\
\text { Shotcrete,t= } 100 \mathrm{~mm} \text { di } \\
\text { dalam terowongan }\end{array}$ & I & $\mathrm{K}$ & 3 & 4 & 6 \\
\hline $\begin{array}{c}\text { Pipa perporasi PVC } \\
\text { dia } 50 \mathrm{~mm} \text {, Untuk } \\
\text { drainase }\end{array}$ & $\mathrm{K}$ & $\begin{array}{l}\mathrm{L} \\
\mathrm{M}\end{array}$ & 1 & 2 & 3 \\
\hline \multicolumn{6}{|c|}{ PEKERJAAN BETON } \\
\hline $\begin{array}{c}\text { Drainase samping } \\
\text { ukuran 300mm } \\
\text { ×300mm , pipa PVC } \\
\text { perporasi diameter } 200 \\
\text { mm }\end{array}$ & $\mathrm{L}$ & $\mathrm{N}$ & 2 & 4 & 5 \\
\hline $\begin{array}{c}\text { Besi tulangan ,ulir } \\
\text { untuk struktur inlet } \\
\text {,outlet }, \text { menara intake } \\
\text { dan terowongan }\end{array}$ & $\mathrm{N}$ & $P$ & 5 & 6 & 7 \\
\hline $\begin{array}{l}\text { Dowel bar, besi D16 } \\
\text { dengan pipa PVC } \\
\text { untuk intake structure }\end{array}$ & $\mathrm{P}$ & $\mathrm{R}$ & 1 & 2 & 3 \\
\hline $\begin{array}{c}\text { Weep holes, pipa PVC } \\
\text { dia } 60 \text { mm untuk outlet } \\
\text { structure }\end{array}$ & $\mathrm{R}$ & $\begin{array}{l}\mathrm{T}, \\
\mathrm{U}\end{array}$ & 1 & 2 & 3 \\
\hline $\begin{array}{l}\text { Beton K-225 tipe B, } \\
\text { untuk lining } \\
\text { terowongan }\end{array}$ & $\mathrm{U}$ & W & 4 & 6 & 7 \\
\hline $\begin{array}{l}\text { Beton K-225 Tipe A } \\
\text { untuk struktur inlet dan } \\
\text { outlet, menara intake } \\
\text { dan rumah pintu }\end{array}$ & W & $\mathrm{Y}$ & 8 & 10 & 12 \\
\hline
\end{tabular}




\begin{tabular}{|c|c|c|c|c|c|c|}
\hline & $\begin{array}{c}\text { Bitumen untuk } \\
\text { sambungan konstraksi }\end{array}$ & $\mathrm{Y}$ & Z & 2 & 3 & 4 \\
\hline 6 & \multicolumn{6}{|c|}{ PEKERJAAN DRILLING DAN GROUTING } \\
\hline & $\begin{array}{c}\text { Drilling ,untuk grouting } \\
\text { konsolidasi , } \\
\text { kedalaman sampai } 5 \\
\text { m }\end{array}$ & Z & $\begin{array}{l}\mathrm{ZA} \\
, \mathrm{Z} \\
\mathrm{B}\end{array}$ & 1 & 2 & 3 \\
\hline & $\begin{array}{l}\text { Drilling untuk grouting } \\
\text { tirai , kedalaman dari } 0 \\
\text { m sampai dengan } 20 \mathrm{~m}\end{array}$ & $\begin{array}{l}\mathrm{Z} \\
\mathrm{A}\end{array}$ & $\mathrm{Z}$ & 1 & 2 & 3 \\
\hline & $\begin{array}{c}\text { Grouting Konsolidasi } \\
\text { dan tirai ( Operasional } \\
\text { dan Material ) }\end{array}$ & $\begin{array}{l}\mathrm{Z} \\
\mathrm{C}\end{array}$ & ZE & 7 & 8 & 10 \\
\hline & $\begin{array}{c}\text { Tes air (water test) } 1 \\
\text { Tekanan }\end{array}$ & $\begin{array}{l}Z \\
E\end{array}$ & ZF & 1 & 2 & 3 \\
\hline & Backfill grouting & $\begin{array}{l}\mathrm{Z} \\
\mathrm{F}\end{array}$ & $\begin{array}{c}\mathrm{Z} \\
\mathrm{G} \\
\mathrm{Z} \\
\mathrm{H}\end{array}$ & 2 & 3 & 4 \\
\hline 7 & \multicolumn{6}{|c|}{ PEKERJAAN JEMBATAN } \\
\hline & Besi Tulangan, polos & $\begin{array}{l}\mathrm{Z} \\
\mathrm{H}\end{array}$ & ZJ & 2 & 3 & 4 \\
\hline & Perancah Jembatan & $\begin{array}{l}\mathrm{Z} \\
\mathrm{J}\end{array}$ & ZK & 3 & 4 & 6 \\
\hline & $\begin{array}{l}\text { Beton K-300 tipe } \mathrm{A} \text {, } \\
\text { untuk balok utama }\end{array}$ & $\begin{array}{l}\mathrm{Z} \\
\mathrm{K}\end{array}$ & $\begin{array}{l}\text { ZL } \\
, \mathrm{Z} \\
\mathrm{M}\end{array}$ & 3 & 4 & 5 \\
\hline & $\begin{array}{l}\text { Beton K-225 tipe B } \\
\text { untuk pier dan } \\
\text { abutment jembatan }\end{array}$ & $\begin{array}{l}\mathrm{Z} \\
\mathrm{M}\end{array}$ & Z & 2 & 3 & 4 \\
\hline & $\begin{array}{c}\text { Beton K-350 tipe } \mathrm{A} \text {, } \\
\text { untuk lantai dan balok } \\
\text { diagframa, dan tiang } \\
\text { handrail }\end{array}$ & $\begin{array}{l}\mathrm{Z} \\
\mathrm{O}\end{array}$ & ZP & 5 & 6 & 7 \\
\hline
\end{tabular}

\section{8}

PEKERJAAN LAIN LAIN

c. Menghitung waktu kegiatan dengan menggunakan rumus pada persamaan (1) :

$t=\frac{(a+4 m+b)}{6}$

Keterangan :

$\mathrm{t}=$ waktu kegiatan

$\mathrm{a}=$ waktu optimistik

$\mathrm{b}=$ waktu pesimistik

$\mathrm{m}=$ waktu realistik

d. Menghitung varians menggunakan rumus pada persamaan (5.):

$$
v=\left(\frac{(b-a)}{6}\right)^{2}
$$

Keterangan :

$\mathrm{v}=$ varians waktu

$\mathrm{a}=$ waktu optimistik

$\mathrm{b}=$ waktu pesimistik

e. Menghitung standar deviasi kegiatan dengan menggunakan rumus pada persamaan (6.):

Tabel 2. Waktu,varian dan Standar Deviasi

\begin{tabular}{lllll}
$\mathbf{N}$ & URAIAN & $\mathbf{t}$ & $\mathbf{v}$ & $\mathbf{S}$ \\
$\mathbf{0}$ & PEKERJAAN & & & \\
\hline
\end{tabular}

\begin{tabular}{|c|c|c|c|c|}
\hline \multirow[t]{2}{*}{1} & \multicolumn{4}{|c|}{ PEKERJAAN PERSIAPAN (ITEM UMUM) } \\
\hline & $\begin{array}{l}\text { Mobilisasi peralatan } \\
\text { konstruksi,penyediaa } \\
\mathrm{n} \text { fasilitas kantor dan } \\
\text { air bersih }\end{array}$ & 6.00 & 0.11 & 0.33 \\
\hline \multirow[t]{2}{*}{2} & \multicolumn{4}{|c|}{ PEKERJAAN DEWATERING } \\
\hline & $\begin{array}{l}\text { Dewatering selama } \\
\text { konstruksi di galian } \\
\text { terbuka dan galian di } \\
\text { dalam terowongan }\end{array}$ & 12.00 & 0.44 & 0.67 \\
\hline \multirow[t]{3}{*}{3} & \multicolumn{4}{|c|}{ PEKERJAAN TANAH } \\
\hline & $\begin{array}{c}\text { Galian , semua jenis } \\
\text {,di dalam } \\
\text { terowongan }\end{array}$ & 12.00 & 0.44 & 0.67 \\
\hline & $\begin{array}{l}\text { Timbunan kembali, } \\
\text { material random, } \\
\text { dibelakang bangunan }\end{array}$ & 2.00 & 0.11 & 0.33 \\
\hline \multirow[t]{4}{*}{4} & \multicolumn{4}{|c|}{ PROTECTION AND SUPPORT WORKS } \\
\hline & $\begin{array}{c}\text { Besi Penyangga } \\
\text { (steel support) } \\
\text { termasuk aksesoris } \\
\text { di dalam terowongan }\end{array}$ & 4.17 & 0.25 & 0.50 \\
\hline & $\begin{array}{l}\text { Proteksi dengan } \\
\text { Shotcrete,t= } 100 \mathrm{~mm} \\
\text { di dalam terowongan }\end{array}$ & 4.17 & 0.25 & 0.50 \\
\hline & $\begin{array}{c}\text { Pipa perporasi PVC } \\
\text { dia } 50 \mathrm{~mm} \text {, Untuk } \\
\text { drainase }\end{array}$ & 2.00 & 0.11 & 0.33 \\
\hline \multirow[t]{8}{*}{5} & \multicolumn{4}{|c|}{ PEKERJAAN BETON } \\
\hline & $\begin{array}{l}\text { Drainase samping } \\
\text { ukuran 300mm } \\
\text { x300mm , pipa PVC } \\
\text { perporasi diameter } \\
200 \mathrm{~mm}\end{array}$ & 3.83 & 0.25 & 0.50 \\
\hline & $\begin{array}{l}\text { Besi tulangan ,ulir } \\
\text { untuk struktur inlet } \\
\text {,outlet, menara } \\
\text { intake dan } \\
\text { terowongan }\end{array}$ & 6.00 & 0.11 & 0.33 \\
\hline & $\begin{array}{l}\text { Dowel bar, besi D16 } \\
\text { dengan pipa PVC } \\
\text { untuk intake structure }\end{array}$ & 2.00 & 0.11 & 0.33 \\
\hline & $\begin{array}{l}\text { Weep holes, pipa } \\
\text { PVC dia } 60 \mathrm{~mm} \\
\text { untuk outlet structure }\end{array}$ & 2.00 & 0.11 & 0.33 \\
\hline & $\begin{array}{l}\text { Beton K-225 tipe B, } \\
\text { untuk lining } \\
\text { terowongan }\end{array}$ & 5.83 & 0.25 & 0.50 \\
\hline & $\begin{array}{c}\text { Beton K-225 Tipe A } \\
\text { untuk struktur inlet } \\
\text { dan outlet, menara } \\
\text { intake dan rumah } \\
\text { pintu }\end{array}$ & 10.00 & 0.44 & 0.67 \\
\hline & $\begin{array}{l}\text { Bitumen untuk } \\
\text { sambungan } \\
\text { konstraksi }\end{array}$ & 3.00 & 0.11 & 0.33 \\
\hline 6 & PEKERJAAN DRILLII & G DAN & ROUT & \\
\hline
\end{tabular}




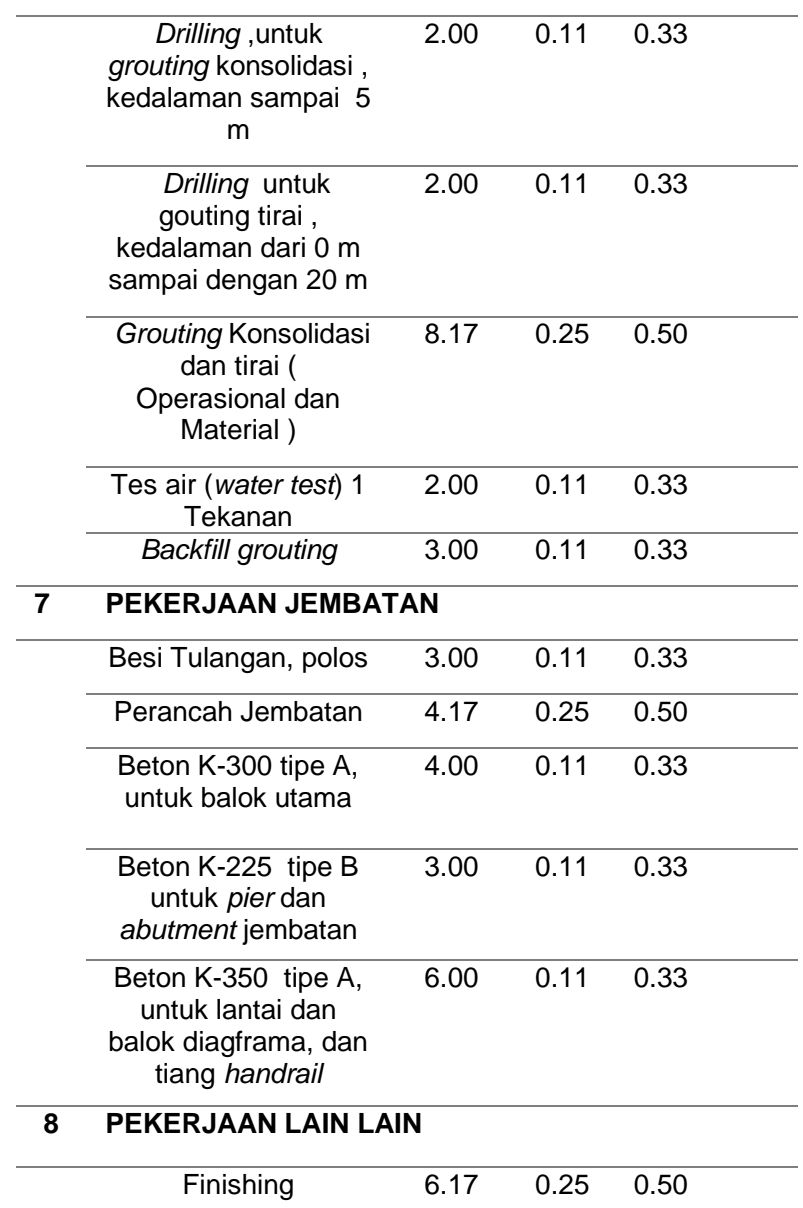

f. Jalur kritis.

Hal pertama yang harus diselesaikan untuk dapat menentukan jalur kritis adalah dengan menghitung 2 waktu awal dan 2 waktu akhir,yaitu Early start - Early finish dan Latest start - Latest finish. Perhitungan dilakukan untuk bagian sisi atas terlebih dahulu sampai pada pekerjaan terakhir, kemudian dari pekerjaan akhir kembali melakukan perhitungan pada kolom bagian bawah hingga pekerjaan awal.

Cara menghitung Early start dan Early finish Early start :Waktu pekerjaan awal dimulai (0) + durasi waktu pekerjaan A (6). Hal ini dilakukan hingga pada pekerjan akhir dengan mengambil nilai terbesar. Early start berada pada bagian atas sebelah kanan pada setiap kolom sebelah kiri. Sedangkan Early finish berada pada bagian atas pada kolom sebelah kanan. Perhatikan Early start pada kolom nomor 1 dan Early finish dengan kolom nomor 2 pada gambar dibawah ini.

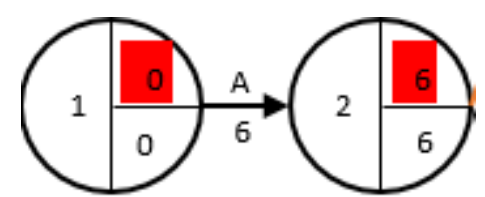

Gambar 2 . Early start (ES)dan Early finish (EF)
Latest start dan Latest finish baru boleh dihitung jika perhitungan early start dan early finish selesai dilakukan dengan cara perhitungan berbanding terbalik. Jika perhitungan early start dan early finish dilakukan dengan penjumlahan dan mengambil nilai terbesar,maka perhitungan Latest start dan Latest finish dilakukan dengan cara pengurangan dan mengambil nilai terkecil,yang perhitungannya dimulai dari pekerjaan akhir ke pekerjaan awal seperti pada gambar dibawah ini.

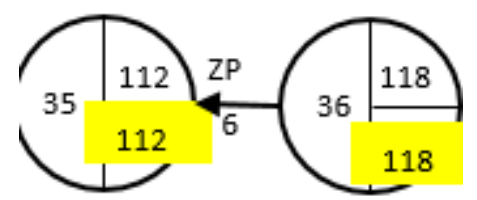

Gambar 3. Latest start (LS) dan Latest finish (LF)

Tabel 3. Jalur Kritis

\begin{tabular}{|c|c|c|c|c|c|c|c|}
\hline $\begin{array}{l}\mathbf{N} \\
\mathbf{O} .\end{array}$ & $\begin{array}{c}\text { URAIAN } \\
\text { PEKERJAAN }\end{array}$ & $\begin{array}{l}E \\
S\end{array}$ & LS & EF & LF & $\begin{array}{l}\text { S } \\
\text { L } \\
\text { A } \\
\text { C } \\
\text { K }\end{array}$ & KET. \\
\hline 1 & \multicolumn{7}{|c|}{ PEKERJAAN PERSIAPAN (ITEM UMUM) } \\
\hline & $\begin{array}{c}\text { Mobilisasi peralatan } \\
\text { konstruksi,penyedia } \\
\text { an fasilitas kantor } \\
\text { dan air bersih }\end{array}$ & 0 & 0 & 6 & 6 & 0 & KRITIS \\
\hline
\end{tabular}

\begin{tabular}{|c|c|c|c|c|c|c|c|}
\hline \multirow[t]{2}{*}{2} & \multicolumn{7}{|c|}{ PEKERJAAN DEWATERING } \\
\hline & $\begin{array}{c}\text { Dewatering selama } \\
\text { konstruksi di galian } \\
\text { terbuka dan galian } \\
\text { di dalam } \\
\text { terowongan }\end{array}$ & 6 & 6 & 18 & 18 & 0 & KRITIS \\
\hline 3 & \multicolumn{7}{|c|}{ PEKERJAAN TANAH } \\
\hline & $\begin{array}{c}\text { Galian, semua jenis } \\
\text {,di dalam } \\
\text { terowongan }\end{array}$ & $\begin{array}{l}1 \\
8\end{array}$ & 18 & 30 & 30 & 0 & KRITIS \\
\hline & $\begin{array}{l}\text { Timbunan kembali, } \\
\text { material random , } \\
\text { dibelakang } \\
\text { bangunan }\end{array}$ & $\begin{array}{l}3 \\
0\end{array}$ & 30 & 32 & 32 & 0 & KRITIS \\
\hline
\end{tabular}

\begin{tabular}{|c|c|c|c|c|c|c|}
\hline \multirow[t]{4}{*}{4} & \multicolumn{6}{|c|}{ PROTECTION AND SUPPORT WORKS } \\
\hline & $\begin{array}{c}\text { Besi Penyangga } \\
\text { (steel support) } \\
\text { termasuk aksesoris } \\
\text { di dalam } \\
\text { terowongan }\end{array}$ & $\begin{array}{ll}3 & 32 \\
2 & \end{array}$ & 36 & 36 & 0 & KRITIS \\
\hline & $\begin{array}{l}\text { Proteksi dengan } \\
\text { Shotcrete,t=100 } \\
\text { mm di dalam } \\
\text { terowongan }\end{array}$ & $\begin{array}{ll}3 & 36 \\
6 & \end{array}$ & 40 & 40 & 0 & KRITIS \\
\hline & $\begin{array}{c}\text { Pipa perporasi PVC } \\
\text { dia } 50 \mathrm{~mm} \text {, Untuk } \\
\text { drainase }\end{array}$ & $\begin{array}{ll}4 & 40 \\
0 & \end{array}$ & 42 & 42 & 0 & KRITIS \\
\hline 5 & \multicolumn{6}{|c|}{ PEKERJAAN BETON } \\
\hline & $\begin{array}{c}\text { Drainase samping } \\
\text { ukuran } 300 \mathrm{~mm} \\
\text { x300mm , pipa PVC } \\
\text { perporasi diameter } \\
200 \mathrm{~mm}\end{array}$ & $\begin{array}{ll}4 & 42 \\
2 & \end{array}$ & 46 & 46 & 0 & KRITIS \\
\hline
\end{tabular}




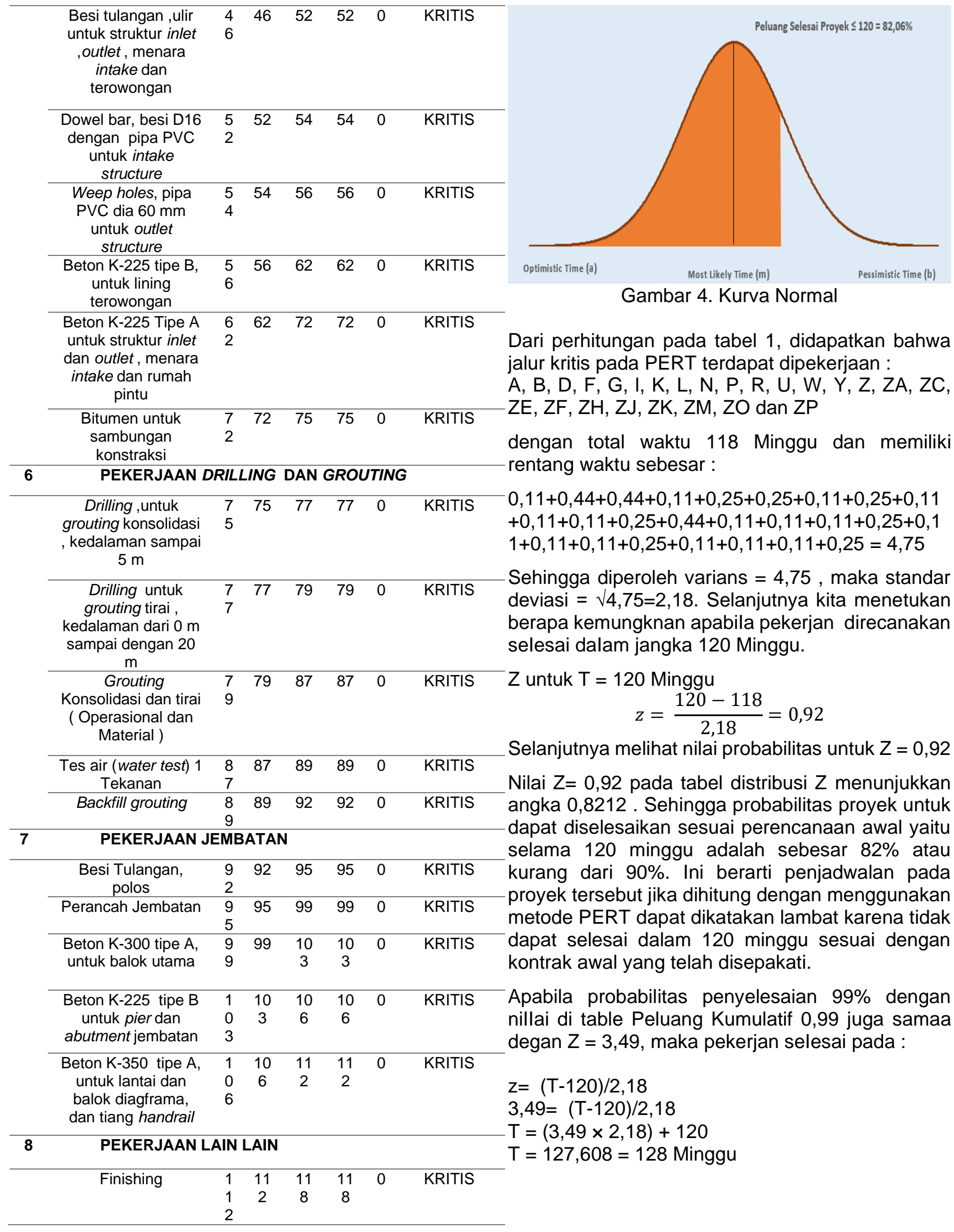

Kemudian digambarkan dalam bentuk kurva menjadi: 


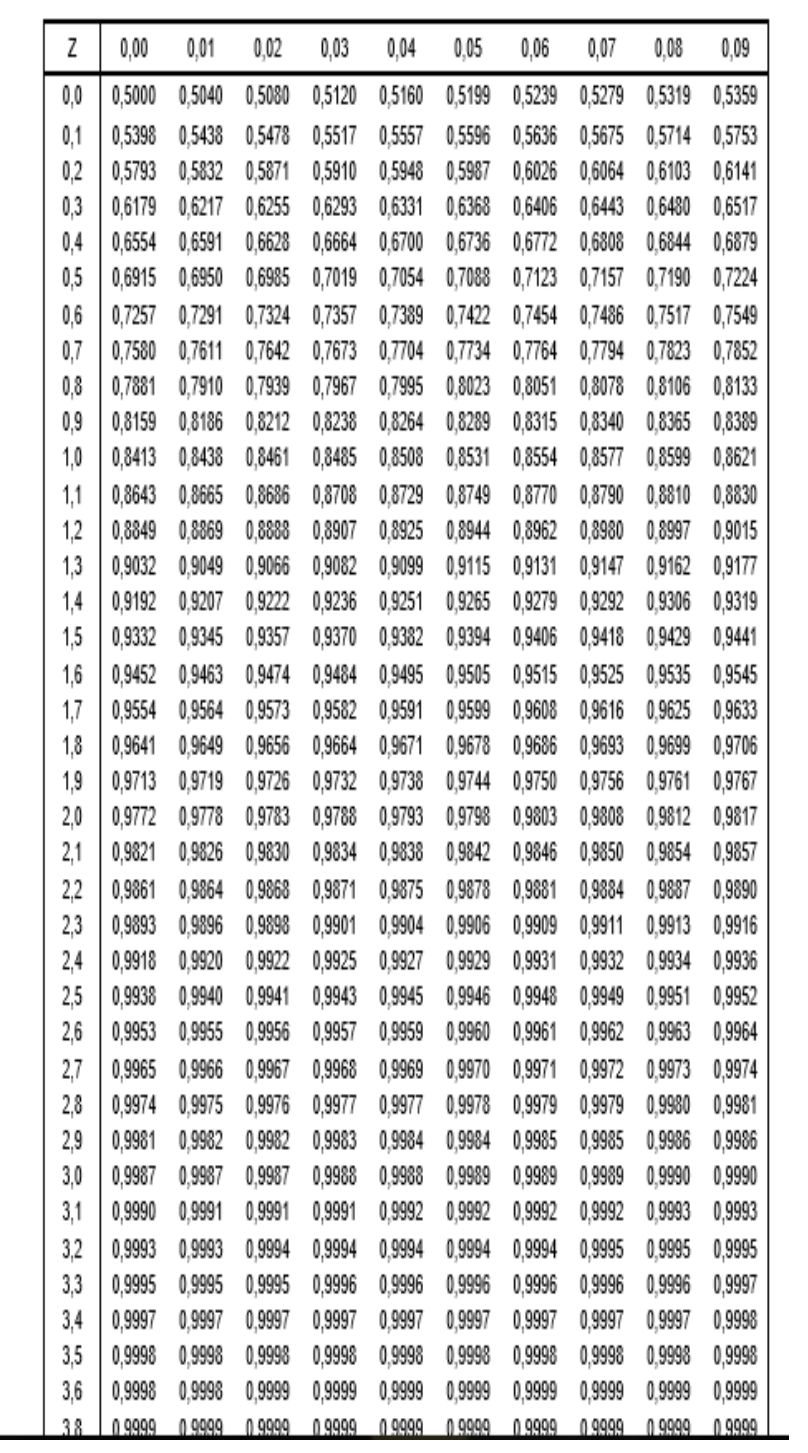

\section{KESIMPULAN}

Setelah mencoba analisis penjadwalan pada metode PERT, maka diperoleh durasi penyelesaian jalur kritisnya selama 118 minggu dengan 25 kegiatan kritis dimana kegiatan tersebut harus selesai tepat waktu, dimana probabilitas selesai sebesar $82 \%$.

Penjadwalan penyelesaian pembangunan proyek Bendungan Karalloe pada sesuai rencana adalah 120 Minggu sedangkan jika menggunakan metode PERT dengan probabilitas 99\% adalah 128 minggu.

\section{DAFTAR PUSTAKA}

[1] A. Angelin dan S. Ariyanti, 2019, "Analisis Penjadwalan Proyek New Product Development Menggunakan Metode PERT
Dan CPM," J. IIm. Tek. Ind., vol. 6, no. 1, doi: 10.24912/jitiuntar.v6i1.3025.

[2] A. A. Nugroho, "Optimalisasi Penjadwalan Proyek Pada Pembangunan Gedung Khusus (Laboratorium) Stasiun Karantina Ikan Kelas 1 Tanjung Mas Semarang," hlm. 99.2007

[3] Amiruddin Hi Muhammad, 2018, "Optimasi Pelaksanaan Proyek Konstruksi Dengan Metode PERT Dan CPM," Open Science Framework, preprint, doi: 10.31219/osf.io/edjb6.

[4] D. Caesaron dan A. Thio, 2015, "Analisa Penjadwalan Waktu Dengan Metode Jalur Kritis Dan Pert Pada Proyek Pembangunan Ruko (JI. Pasar lama no.20, Glodok)," J. Ind. Eng., vol. 8, no. 2, hlm. 24.

[5] I. Raharja, 2014, "Analisa Penjadwalan Proyek Dengan Metode PERT di PT. Hasana Damai Putra Yogyakarta pada Proyek Perumahan Tirta Sani," vol. 2, no. 1, hlm. 14,

[6] M. I. Mas'ud dan E. Wijayanti, 2017, "Analisis Evaluasi Biaya dan Penjadwalan Waktu Proyek Pengolahan Limbah PT. KI dengan Pendekatan PERT," J-ENSITEC, vol. 3, no. 2, Mei 2017, doi: 10.31949/j-ensitec.v3i2.644.

[7] N. Rahayu dan G. H. Nugraha, 2018, "Evaluasi Penjadwalan Proyek dengan Metode PERT pada Pembuatan Pabrik PT. Daya Kobelco," hIm. 6.

[8] P. L. A. Luthan, "Luthan, Putri Lynna A.2006, "Aplikasi Microsoft Project untuk Penjadwalan Kerja Proyek Teknik Sipil / Putri Lynna A. Luthan, Syafriandi; Editor: Renati Winong" hlm. 1.

[9] R. D. Irawati, 2017, "Analysis Of Project Implementation Using The PERT Method (Case Study Of Type 165 Building Project The Nusa Penida House Blitar City)," vol. 01, no. 07, hIm. 10.

[10] S. Suherman, 2016, "Analisa Penjadwalan Proyek Menggunakan PDM dan Pert Serta Crash Project (Studi kasus: Pembangunan Gedung Main Power House PT. Adhi Karya)," J. Tek. Ind. J. Has. Penelit. Dan Karya IIm. Dalam Bid. Tek. Ind., vol. 2, no. 1, hlm. 31, Jun 2016, doi: 10.24014/jti.v2i1.5061. 